\title{
Introduction of Scrum in An Elite Team: A Case Study
}

\author{
Atefeh Khosravi ${ }^{1}$, Taghi Javdani Gandomani2 ${ }^{*}$, Hossein Fahimian ${ }^{3}$ \\ ${ }^{1}$ Dept. of Computer Eng., Islamic Azad University, Farsan Branch, Farsan, Iran. \\ 2 Dept. of Computer Eng., Islamic Azad University, Boroujen Branch, Boroujen, Iran. \\ ${ }^{3}$ Sama Technical and Vocational Training College, Islamic Azad University, Roudehen Branch, Tehran, Iran. \\ * Corresponding author. Tel.: +98-9131055201 email: t_javdani@azad.ac.ir \\ Manuscript submitted December 2, 2016; accepted February 27, 2017. \\ doi: $10.17706 /$ jsw.12.3.173-179
}

\begin{abstract}
Scrum as one of the most popular software methodologies, has been growly employed by software teams and companies in recent years. This method provides several simple and effective practices to manage software projects. However, despite of its simple structure, lots of challenges and issues have been reported during Scrum adoption. Te main aim of this paper is to report the main issues of introducing Scrum in a particular team. Team members had been selected within a nomination process. The adoption process took about 6 months, and adoption proceeded during a real, but not critical project. Results showed several challenges and barriers the team faced with. The most critical issues were regarding team collaboration and commitment. Moreover, collaboration with product owner and sprint planning were the others major issues. Finally, while the results showed a few challenges regarding planning game and retrospective meeting, no challenge has been reported regarding tools and technology.
\end{abstract}

Key words: Agile software development, agile methods, scrum, scrum adoption.

\section{Introduction}

Employing a proper software development methodology is a critical factor which affects the success rate of software project dramatically. Methodology selection should be done based on the existing pains, limitations, abilities, and needs of software companies, customers, and projects [1].

Scrum is one of the well-known software development framework which helps software teams to manage their projects in a proper manner. Recently, many companies intend to employ this framework especially when they are exposed to the project management related issues. Scrum tries to handle the project management issues via a simple manner in a collaborative environment. However, it seems that many software teams and practitioners face with serious issues, barriers, and challenges when adopting this method [2]-[4]. As an Agile method process, Scrum is subjected to the Agile methods associated challenges and issue. This makes the adoption process harder than expected compared to the disciplined methodologies [5].

Several studies reported challenges of Scrum adoption and a few provided some advices, strategies, or ad-hoc facilitators to improve the quality of the adoption process. For instance, in some studies, training has been addressed as serious facilitator to cope with the adoption related issues [6], [7]. Furthermore, selection of talented people and taking advantages from full-time mentoring services were reported as other supporting factors to avoid the challenges of Scrum and other Agile methods adoption [8], [9]. However, in all studies there were no specific process for people nomination and hiring appropriate and 
talented experts for conducting the adoption process.

This study particularly focused on exploring critical challenges when a talented team tries to employ Scrum methodology and adapt to it. The next parts of this paper are as follows: Section 2 introduces Scrum framework, its positions among the other development processes, and its specific practices. Section 3 explains the research design adopted in the study, continued by Section 4 which presents the initial results of the study. Section 5, provides a brief discussion on the findings, and finally, Section 6 concludes the paper.

\section{Scrum}

Scrum was introduced as one the earliest Agile methods and officially joined to them when its developers signed the Agile manifesto in 2001 [10]. Project management is the main focus of Scrum where it had been addressed as one of the most of critical failure factors of software projects. As an Agile method, Scrum conforms Agile values and principles indicated by Agile manifesto and its supplementary document. The framework of Scrum is suitable for handling of complex projects, as indicated by its developers. Fig. 1 shows the nutshell of the Scrum framework.

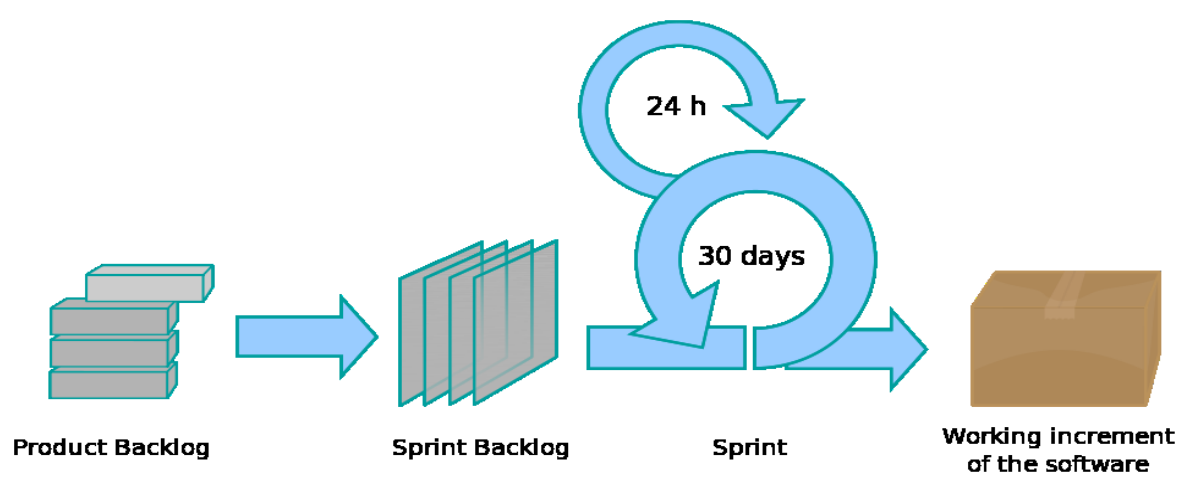

Fig. 1. Scrum framework.

The rationale behind Scrum is the reality of requirements changing in software projects. Scrum promotes team collaboration and productivity by defining particular roles, activities, and artifices. Defining only a few concepts (three roles, three activities, and three artifacts) has made scrum as a flexible and Agile software development process. Scrum emphasizes on role of an on-site customer, called as Product Owner, as one the development team members [11]. Moreover, it promotes self-organization as an essential requirement of team working which causes improvements of team productivity and performance [12]. Furthermore, considering a few particular practices such as daily stand-up meeting, review and retrospective meeting, and planning, results in better quality of team working, and therefore, quality of the product.

Scrum is people-centric by its nature. Thus, all of its concepts are typically related to the people involved in the Scrum development team. This dimension of Scrum leads to both positive and challenging issues, as reported by the previous studies.

\section{Research Design}

This study was started by a nomination process which tried to select the most talented software developers to participate as Scrum development team members. Fig. 2 simply shows the adopted steps of the research.

A qualified expert team (called as 'selection committee') including two Scrum coaches, one Scrum master, 
one Product Owner, and one Project manager, was responsible to select competent team members among the available and interested candidates. The company under study, had more than 15 years experience in software development with more than 65 software developers in various roles and professions. The goal of the nomination process was selection of 7 to 10 experts as the pilot team to start Scrum adoption in the company.

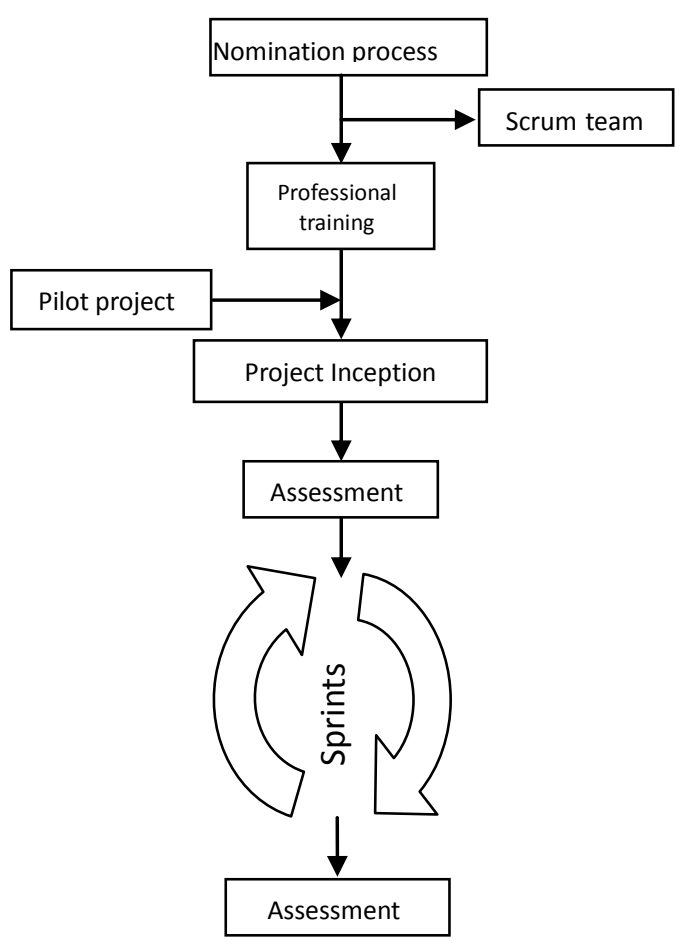

Fig. 2. Research Process adopted in the study.

In the past three months, two theoretical workshops had been held to introduce Agile approach, its principles and values and initial introduction of Agile methods, especially Scrum and XP. Almost all of the developers had attended to the workshops; thus, it seemed that they had initial knowledge about Agile approach. The nomination process was started by publishing a call for competition notice inside the company. At the end of the deadline, 37 volunteers had been registered. Selection committee eventually selected 9 candidate experts (called as pilot team). Table 1 shows demography of the nominated experts.

Table 1. Demography of the Pilot Team Members

\begin{tabular}{cccc}
\hline No. & $\begin{array}{c}\text { SD Experience } \\
\text { (years) }\end{array}$ & $\begin{array}{c}\text { Experience in company } \\
\text { (years) }\end{array}$ & Education \\
\hline P1 & 7 & 4 & BS \\
P2 & 6 & 3 & BS \\
P3 & 5 & 3 & MS \\
P4 & 5 & 3 & BS \\
P5 & 5 & 4 & BS \\
P6 & 6 & 5 & BS \\
P7 & 7 & 2 & MS \\
P8 & 5 & 2 & BS \\
P9 & 6 & 5 & BS \\
\hline \hline
\end{tabular}

Next step was providing the pilot team with Scrum professional training during theoretical and practical training courses. After one week training, they started working on a pilot project. Pilot project also was 
selected by selection committee by considering the related issues [13]. Pilot project was a real, but not critical project. The customer was intended to carry out his project as a pilot project and introduced his representative to join the pilot team as Product Owner. Fortunately, the Product Owner had about 3 years experience in his role and attended the training courses like the nominated developers. An experienced Scrum master also was added to the pilot team.

Pilot project included 6 sprints as the pilot team had planned. At the end of each sprint researchers evaluated the progress and quality of adoption based on the pre-defined criteria. It should be noted that an Agile coach was available in the site during the project. Finally, at the end of the project, all the collected data were analyzed and initial results have been reported. Data collection and analysis has been done in a mix method approach. The next section provides initial results of the study briefly.

\section{Results}

Data analysis showed positive and negative aspects of the adoption process in the pilot team. Employing a full-time Agile coach was essentially beneficial.

\subsection{Positive Aspects}

Selection of the most competent team members had strongly positive impacts on the adoption process. Several points have been explored as positive points of the adoption process as follows:

- Early wins: getting early wins was a positive point in the project which indicated that talented and well-trained experts can adapt themselves easier to the new practices.

- Positive atmosphere of review meeting: almost all sprint reviews were positively approved by the customer. However, a few comments raised by the customer to enrich the quality of the product increments.

- Good retrospective meeting: retrospective meetings held in a good manner and without addressing a critical issue. Tough, a few suggestions raised by team members, no one complain about the adoption process and its necessary requirements.

- No technical problem: team members employed some of the Agile project management tools such as VersionOne package, Easybacklog, and Microsoft excel. Fortunately, no problem or challenge has seen during the process.

- No communication challenge: team members were working together in one site. Thus, face to face communication was extremely easy. Furthermore, quality of communications was reported as well-accepted by both team members and researchers.

- No resistance against change: No resistance against change of the development practices had been in the adoption process.

\subsection{Negative Aspects}

Despite of the above positive aspects, several negative points have reported in this study. Almost all of them are associated with people and their behaviors.

- Lack of enough collaboration: despite of getting early wins, data analysis revealed that some of the team members complained about inadequate collaboration between team members as they expected.

- Lack of enough commitment: in some situations, less commitment to the goals of the pilot teams has been reported by the team members. This point had raised mainly when they were asked to breakdown the user stories before each sprint. Also, stand up meeting was negatively affected by low attendance rate. This point also had been seen when team members asked to attend to planning game meeting. 
- Product Owner issues: the attended Product Owner had a good background in his role. Nonetheless, there were a few problems with his collaboration with some of the developers.

\section{Concise Discussion}

Introducing any new method, practice, or even technology always is exposed to people resistance against the change. This research showed no considerable resistance against acceptation of new practices. This is in contrary with what were previously reported by other researchers $[14,15]$. This can be the result of the nomination process whereby only the qualified and talented people have been nominated for the adoption process. No resistance against the change process and no problems with the tools have been reported.

Getting early wins was previously addressed as a critical success factor of adoption of Agile methods [5], [16], [17]. This can be a good point in this process, especially when the workers are knowledge workers whom voluntarily attended to the team developments.

Furthermore, both review and retrospective meetings had held in a positive atmosphere which both customers and developers had a good relationship and collaboration.

Finally, no problems have reported in employing new technologies and software packages which support the Scrum framework. Moreover, communication quality in this case study was favorable, while it has been addressed as aserious challenge area in Agile teams by the previous studies.

On the other hand, a few negative points were reported which mainly they were associated with human behaviors. For instance, lack of enough commitment to the adoption process and lack of enough collaboration were seen by the team members and researchers. Eventually, there were some issues regarding team members and development team collaboration. These points in some of the previous studies have been addressed as a challenge area $[18,19]$.

\section{Conclusion}

This paper reports the results of a Case study on introduction of Scrum in a real environment. Although the literature review showed this process is not easy, many software teams and companies are intended to experience. This study focused on selection of a talented team to adopt Scrum in a pilot project. Nomination process led to less challenge areas, mainly because the talented people are able to cope with the potential challenges. Getting early wins, motivates the team members to work more productively and better process improvement. Also, no considerable people resistance and communication issues were reported. However, a few challenges were reported which were related to people, their collaboration with the others, and lack of enough their collaboration with the other team members. In the other hand, no issues have been addressed in using special tools or technologies to support Scrum process.

\section{References}

[1] Petty, M. D., Kim, J., Park, S., \& Lee, S. (2016). A methodology for quantitative assessment of the features and capabilities of software frameworks for model composition. International Journal of Modeling, Simulation, and Scientific Computing, 7(1), 1541002.

[2] Akif, R., \& Majeed, H. (2012). Issues and challenges in Scrum implementation. International Journal of Scientific and Engineering Research, 3(8), 1-4.

[3] Gupta, R. K., \& Manikreddy, P. (2015). Challenges in adapting scrum in legacy global configurator project. Proceeding of 10th International Conference on Global Software Engineering (pp. 46-50)

[4] Santos, A. R., Sales, A., Fernandes, P., \& Nichols, M. (2015). Combining challenge-based learning and scrum framework for mobile application development. Proceeding of Proceedings of the 2015 ACM Conference on Innovation and Technology in Computer Science Education pp. (189-194) 
[5] Gandomani, T. J., \& Nafchi, M. Z. (2016). Agile transition and adoption human-related challenges and issues: A Grounded Theory approach, Computers in Human Behavior, 62 257-266.

[6] Gandomani, T. J., Zulzalil, H., Ghani, A. A. A., Sultan, A. B. M., \& Sharif, K. Y. (2014). Exploring facilitators of transition and adoption to agile methods: A grounded theory study. Journal of Software, 7(9), 1666-1678.

[7] Offner, A., Swindler, S., Padula, G., King, A., Fedora, J., \& Malone, L. (2011). Change management: Developing a tool to foster adaptive collaboration. Proceeding of 12th International Conference on Collaboration Technologies and Systems, pp. (606-611).

[8] Gandomani, T. J., Zulzalil, H., Ghani, A. A. A., Sultan, A. B. M., \& Sharif, K. Y. (2014). How human aspects impress Agile software development transition and adoption. International Journal of Software Engineering and its Applications, 8(1), 129-148.

[9] Moreira, M. E. (2013). Establishing an agile education program. Being Agile, (161-166).

[10] Beck, K., Cockburn, A., Jeffries, R., \& Highsmith, J. (2001). Agile Manifesto. Retrieved from: http://www.agilemanifesto.org

[11] Cohn, M. (2009). Succeeding with Agile: Software Development Using Scrum. Boston, MA: Addison-Wesley Professional.

[12] Scrum-Alliance. (2012, Jan. 2012). What is Scrum? Retrieved from: http://www.scrumalliance.org/

[13] Gandomani,T. J., Zulzalil, H., Ghani, A. A. A., Sultan, A. B. M., \& Sharif, K. Y. (2013). Exploring key factors of pilot projects in agile transformation process using a grounded theory study.

[14] Bayona, S., Calvo-Manzano, J. A., \& Feliu, T. S. (2012). Critical success factors in software process improvement: A systematic review.

[15] Hong, W., Thong, J., Chasalow, L., \& Dhillon, G. (2011). User acceptance of agile information systems: A model and empirical test. Journal of Management Information Systems, 28(1), 235-272.

[16] Duka, D. (2013). Adoption of agile methodology in software development. Proceeding of 36th International Convention on Information and Communication Technology, Electronics and Microelectronics.

[17] Ganesh, N., \& Thangasamy, S. (2012). Lessons learned in transforming from traditional to agile development. Journal of Computer Science, 8(3), 389-392.

[18] Gandomani, T. J., Zulzalil, H., Ghani, A. A. A., \& Sultan, A. B. M. (2013). Important considerations for agile software development methods governance. Journal of Theoretical and Applied Information Technology, 55 (3), 345-351.

[19] Conboy, K., Coyle, S., Wang, X., \& Pikkarainen, M. (2011). People over process: Key challenges in agile development. IEEE Software, 28(4), 48-57.

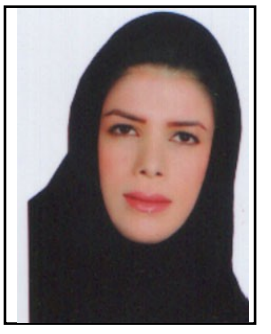

Atefeh Khosravi received a master degree from Islamic Azad University, Shahrekord branch at 2016. She is working on software methodologies adaptation and empirical software engineering a member of a research group.

Her research interests are software development methodologies and software process improvement.

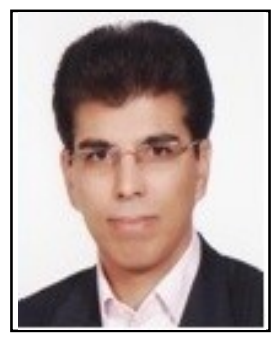

Taghi Javdani Gandomani received his BS in software engineering from Isfahan University of Technology, Isfahan, Iran (1997) and a MS in software engineering from Isfahan University, Isfahan, Iran (2000). He also received his Ph.D. from Universiti Putra 
Malaysia (UPM) at 2014 in software engineering. Now, he is an assistant professor in Islamic Azad University, Iran. His research interests are Agile software development, empirical software engineering, and software quality. He also directs a young and talented research group.

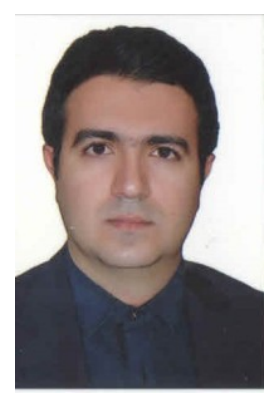

Hossein Fahimian has graduated with a MS degree in computer system architecture engineering from Iran University of science and technology, Tehran, Iran, 2008. He has about 5 years experience at IT departments in some companies as a technical manager and consultant.

Teaching \& research and lecturer position at the university led him to get member of faculty (Instructor) at Islamic Azad university (2009).

He has published some aarticles in WSN, Networks. 